\title{
Does Herding Affect Volatility? Implications for China's Stock Market
}

\author{
Yi-Chang Chen \\ Accounting School, Nanfang College of Sun Yat-sen \\ University, China \\ E-mail: Phdchen7219@gmail.com
}

\author{
Yixuan Fu*, Yuwen Yang, Yitian Chen \\ *Accounting School, Nanfang College of Sun Yat-sen \\ University, China \\ E-mail:942448419@qq.com \\ *Corresponding author
}

\begin{abstract}
Behavior biases affect investors' financial decisions in many ways such as herding behavior, which is the tendency for individuals to mimic the actions of a larger group. The purpose of the paper is to examine whether the herding causes volatility using daily data in Shanghai composite index. The results confirm that herding behavior makes a great influence on stock price volatility and a stable stock market based on the GARCH model in the periods of financial crisis of 2008 to 2010. The evidence indicates the effect is associated with market conditions, investors' expectation, regulated market, and stock market cointegration.
\end{abstract} crisis

Keywords-Volatility; Herding behavior; GARCH; Financial

\section{INTRODUCTION}

Herding behavior of investors can be defined as the tendency of the investors to imitate the actions of other market participants, thus ignoring their own information and beliefs. (Filip et al., 2015) [7]. Herding is often used to describe the correlation resulting from interactions between investors. (Chiang and Zheng, 2010) [4].

At present, many studies investigated the existence of herding effects or focus on the impacts of analysts and firms' characteristics (Zhou and Lai, 2009; Tan et al., 2008) [15] [12]. In different situations, the level of herding behavior is different, such as different market conditions (Yao et al., 2014) [13], different industries (Camara, 2017) [2]. In addition, herding behavior can be either rational or irrational (Guo and Wu, 2004) [8]. Participants' herd mentality affects the rate of fluctuations in stock prices, thereby inducing irrational behavior. This behavior has affected the stability of the entire China's stock market. Therefore, it is of great theoretical and practical significance to explore the influence of herding behavior on stock market volatility.

This paper explores the relationship between investors' herding behavior and stock market volatility, focusing on whether there is a herding behavior in China's stock market, and whether herding behavior will affect stock market volatility. Apart from that, this paper analyzed the important influence of stock investors' herding behavior on financial activities, and thus understands the rules of the stock market.
The paper is organized as follows: Section 2 focuses on a review of previous studies. Section 3 illustrates the method and data. Empirical analysis is shown in Section 4, and Section 5 offers conclusions.

\section{LITERATURE REVIEW}

For the method of measuring herding behavior, previous studies have made contributions. Christie and Huang $(\mathrm{CH})$ (1995) first proposed to use the rate of dispersion as an indicator [5]. They used CSSD (Cross-Sectional Standard Deviation) to test the herding behavior and found that investors usually give up their inherent behaviors and fluctuate with the market volatility. Chang, Chen and Khorana (CCK) (2000) improved the $\mathrm{CH}$ model by using the cross-sectional absolute deviation (CSAD) of market yield to measure the herding behavior [3]. Hwang and Salmon (2001) proposed a model based on the cross-sectional dispersion of asset sensitivity in a given market condition [9]. The study showed that when the market is in a relatively stable period, it has a more pronounced herding behavior than the market is in a period of large fluctuations.

Shah et al. (2017) sorted firms into small and large groups based on median market capitalization, results indicate that large firms show herding behavior in extreme market movements [11]. Zheng et al. (2017) indicates that industry herding is more pronounced in down markets and low trading volume markets for most markets [14]. Herding behavior is also more pronounced under conditions of declining markets (Yao et al., 2014) [13]. In addition, Camara (2017) examined herding behavior in capital structure of firms for four major US industries: Manufacturing, construction, wholesale and services [2]. The conclusion showed that in the bear market, the herding behavior exists in the service industry. In the bull market, the herding exists in the manufacturing industry. Hwang and Salmon (2008) found that when the market was relatively stable, the herding behavior was more serious than when the market was in a crisis, and it was found that investors in the crisis were more inclined to look for fundamental values rather than blindly following the market [10]. 


\section{METHOD}

This study uses statistical analysis of data, the software including R, Eviews 8.0. We explore the impact of herding behavior on stock market volatility.

\section{A. Stationary test}

This study used the Augmented Dickey Fuller (ADF) method to verify the existence of unit roots in the time series. The test is based on the AR (m) model, and the regression model formula is:

$$
\Delta Y_{t}=\alpha_{0}+\gamma_{t}+\beta_{1} Y_{t-1}+\sum_{i-1}^{m} \delta_{i} \Delta Y_{t-1}+\varepsilon_{t}
$$

Where $Y_{t}$ represents the predicted variable; $Y_{t}: Y_{t}=Y_{t}-Y_{t-i}$, indicating the first-order difference; $\alpha_{0}$ is the intercept term; $\gamma, \beta_{1}, \delta_{1}$ represents the decision coefficient; $t$ represents the time trend term; $\varepsilon_{t}$ indicated as a residual term and in line with white noise. The $m$ in the formula indicates the most appropriate number of lag periods, which can make the residual term approximate white noise. When $Y_{t}$ is not stationary $t$, that is, it has a unit root, then $\beta_{1}=0$; and when $Y_{t}$ is stationarity, that is, does not have a unit root, then $\beta_{1} \neq 0$. Therefore, the null hypothesis can be set as:

$H_{0}: \beta_{1}=0$ (The sequence has a unit root, which is a time series with no stationarity)

$H_{0}: \beta_{1}=0$ (The sequence has no unit root, which is a time series with stationarity)

If the result of the ADF test is that the null hypothesis is not rejected, it means that the sequence has a unit root. In this case, the sequence is differentiated, and then the differential sequence is subjected to ADF test until the test sequence rejects the null hypothesis.

\section{B. ARCH test}

The ARCH model takes into account the fact that the conditional variability will change according to the change of time, and the conditional variance will be affected by the square of the residual term in the previous period. The ARCH (q) model, is defined as follows:

$$
\begin{gathered}
Y_{\mathrm{t}}=X_{t} \beta+\varepsilon_{t} \\
Y_{\mathrm{t}} \mid \Omega_{-1} \sim N\left(X_{t} \beta, \sigma_{t}^{2}\right) \\
\sigma_{t}^{2}=\alpha_{0}+\sum_{i=1}^{q} \alpha_{i} \varepsilon_{t-1}^{2} \\
\varepsilon_{t}=Y_{t}-X_{t} \beta \\
\varepsilon_{t} \mid \Omega_{t-1} \sim N\left(0, \sigma_{t}^{2}\right)>0, \alpha_{t}>0, i=1,2,3 \ldots, q
\end{gathered}
$$

Where: $Y_{t}$ is the time series data of the ARCH process; $t_{1}$ is the collection of all available information when it reaches the $t-1$ period; $X_{t} \beta$ is a linear combination of endogenous and exogenous variables that can be obtained in $\Omega_{t-1} ; \sigma_{t}^{2}$ represents the conditional variation of $Y_{t}$, which is affected by the period $q$ residual term; $\alpha, \beta$ : the unknown parameter vector of the ARCH process; $q$ is the order of the ARCH process.

In the literature of the ARCH model, the formula (2) is often referred to as the average equation, and the formula (3) is called the variation function.

Therefore, if $X_{t}$ in the average equation represents ARMA in a single time series, the $X_{t}$ backward term in the equation is $m$, the backward term of MA is $n$, and the heterogeneous variation is $\mathrm{ARCH}$ (q). At this point, the average equation and the ARCH variance equation can be combined to represent $\operatorname{ARMA}(\mathrm{m}, \mathrm{n})-\operatorname{ARCH}(\mathrm{q})$. The formula is:

$$
\begin{aligned}
& Y_{t}=\beta_{0}+\sum_{i=1}^{m}+\varepsilon_{t}+\sum_{i=1}^{n} \gamma_{i} \varepsilon_{t-i} \\
& \sigma_{t}^{2}=\alpha_{0}+\sum_{i=1}^{q} \alpha_{i} \varepsilon_{t-1}^{2}
\end{aligned}
$$

\section{GARCH test}

Bollerslev (1986) extended the ARCH model to the GARCH model ${ }^{[1]}$. The number of parameters of the GARCH model is more compact than that of the ARCH model, making the structure of the backward term more flexible. According to the GARCH-M model developed by Engle et al. (1987) ${ }^{[6]}$, the formula used is:

$$
Y_{t}=X_{t} \beta+\sigma_{t}^{2} C S A D_{t}+\varepsilon_{t}
$$

And add dummy variables to measure the behavior of stock returns and volatility during the financial crisis. The model for this study is set to:

$$
\begin{gathered}
\varepsilon_{t} \mid \Omega_{t-1} \sim N\left(0, \sigma_{t}^{2}\right) \\
R_{t}=\sum_{i=1}^{m} \delta_{i} R_{t-i}+\mu \sigma_{t}^{2}+C S A D_{t}+\varepsilon_{t} \\
\sigma_{t}^{2}=\alpha_{0}+\sum_{i=1}^{p} \alpha_{i} \varepsilon_{t-j}^{2}+\sum_{j=1}^{q} \beta_{j} \sigma_{t-j}^{2}+C S A D_{t} \\
p \geq 0, q>0 \\
\alpha_{0}>0, \alpha_{t} \geq 0, i=1,2, \ldots, q \\
\beta_{j} \geq 0, j=1,2, \ldots, p
\end{gathered}
$$

$Y_{t}$ is the time series data of the GARCH process; $\Omega_{t-1}$ is the set of available information collected to $t-1 ; \sigma_{t}^{2}$ is the conditional variation of $Y_{t}$, which is subject to the period $\mathrm{q}$ residual term and Influence of the period $\mathrm{p}$ conditional variation; $\delta_{i}, \mu, \varepsilon, \gamma, \alpha_{i}, \beta_{j}$ are expressed as unknown parameter vectors of the GARCH process; $\mathrm{p}$ and $\mathrm{q}$ are the orders of the GARCH process; $D_{t}$ is the crisis dummy variable, when $D_{t}=0$, it indicates that the period $\mathrm{t}$ is a non-crisis event; when $D_{t}=1$, it indicates that the period $\mathrm{t}$ is a crisis event. 


\section{EMPIRICAL ANALYSIS}

This study used the yields of Shanghai Composite Index of these three events: the Subprime lending crisis from January 1st, 2008 to February 12th, 2008, the Lehman Brothers crisis from September 19th, 2008 to November 20th, 2008, the European sovereign debt crisis from June 9th, 2008 to April 16th, 2010 to analyze the data.

\section{A. Data analysis result}

\section{1) Basic statistic test}

Through Eviews 8.0, the basic statistics of three financial events are calculated. The results are shown in Table 1.

TABLE I. BASE QUANTITY TEST

\begin{tabular}{|lcccccc|}
\hline & \multicolumn{2}{c}{$\begin{array}{c}\text { Subprime lending } \\
\text { crisis }\end{array}$} & \multicolumn{2}{c|}{$\begin{array}{c}\text { Lehman Brothers } \\
\text { crisis }\end{array}$} & \multicolumn{2}{c|}{$\begin{array}{c}\text { European sovereign debt } \\
\text { crisis }\end{array}$} \\
\hline & Rm & CSAD & Rm & CSAD & Rm & CSAD \\
\hline Mean & -0.005 & 0.020 & 0.002 & 0.029 & -0.005 & 0.013 \\
Median & 0.002 & 0.009 & -0.007 & 0.025 & -0.004 & 0.011 \\
Maximum & 0.081 & 0.081 & 0.095 & 0.095 & 0.035 & 0.051 \\
Minimum & -0.072 & 0.001 & -0.06 & 0.002 & -0.051 & 0.000 \\
Std.Dev. & 0.030 & 0.024 & 0.037 & 0.022 & 0.018 & 0.013 \\
Skewness & -0.033 & 1.609 & 0.518 & 1.176 & 3.775 & 4.358 \\
Kurtosis & 5.002 & 4.209 & 2.977 & 3.849 & 2.084 & 38 \\
Jarque-Bera & 4.179 & $12.314^{* * *}$ & 1.788 & $10.416^{* * *}$ & 40 & $14.596^{* * *}$ \\
N & 25 & 25 & 40 & 40 & 38 \\
\hline
\end{tabular}

2) Stationary test result $\quad$ financial events was stationary. The results are shown in Table

In this study, the ADF test method was used to check whether the yield of Shanghai composite index during the three

2. The results show that the data rejects the null hypothesis, does not have a unit root, and has stationarity.

TABLE II. STATIONARY TEST

\begin{tabular}{|ccc|}
\hline Subprime lending crisis & Lehman Brothers crisis & European sovereign debt crisis \\
\hline$-3.788^{* * *}$ & $-3.627^{* * *}$ & $-3.633^{* * *}$ \\
-3.831 & $-3.670^{* * *}$ & $-3.646^{* * *}$ \\
$-3.809^{* * *}$ & $-3.621^{* * *}$ & $-3.662^{* * *}$ \\
\hline
\end{tabular}

Note: *,** and *** represent statistical significance at the $10 \%, 5 \%$ and $1 \%$ levels, respectively.

3) Test result of Ljung-Box Q-statistics

The results calculated by Eviews8.0 are shown in Table 3

The compensation sequence has a first-order autocorrelation.

TABLE III. Q-STATISTIC TEST

\begin{tabular}{|c|c|c|c|}
\hline & e lending crisis & Lehman Brothers crisis & European sovereign debt crisis \\
\hline \multicolumn{4}{|c|}{ Panel A: Ljung-Box Q-tests } \\
\hline $\mathrm{LB} Q(1)$ & 0.191 & 0.049 & 0.339 \\
\hline $\mathrm{LB} Q(2)$ & 0.292 & 0.208 & 4.360 \\
\hline LB Q(6) & 5.286 & 4.233 & $12.936^{* *}$ \\
\hline LB Q(9) & 10.16 & 5.065 & $17.196^{* *}$ \\
\hline $\mathrm{LB} Q(12)$ & 12.571 & 7.238 & $20.066^{*}$ \\
\hline $\mathrm{LB} \mathrm{Q}^{2}(2)$ & 0.111 & 0.427 & 0.054 \\
\hline $\mathrm{LB} \mathrm{Q}^{2}(3)$ & 0.124 & 0.52 & 0.222 \\
\hline $\mathrm{LB} \mathrm{Q}^{2}(6)$ & 2.453 & 3.165 & 1.318 \\
\hline $\mathrm{LB}^{2}(9)$ & 5.885 & 6.029 & 3.252 \\
\hline $\mathrm{LBQ}^{2}(12)$ & 6.863 & 8.688 & 10.985 \\
\hline
\end{tabular}

Note: LB Q() represnts Ljung-Box Q-tests for autocorrelation by

including various lags in the test statistic.

4) AIC test result

Configure the most suitable ARMA model with Eviews 8.0.

The results are shown in Table 4. 
TABLE IV. AIC TEST RESULTS

\begin{tabular}{|lccc|}
\hline & $\begin{array}{c}\text { Subprime lending } \\
\text { crisis }\end{array}$ & $\begin{array}{c}\text { Lehman Brothers } \\
\text { crisis }\end{array}$ & \multicolumn{2}{c|}{ European sovereign debt } \\
crisis
\end{tabular}

5) LM test

The LM test can determine whether the reward sequence has a second-order autocorrelation. The results are as follows:

TABLE V. ARCH-LM TEST RESULTS

\begin{tabular}{lc}
\hline Part A: Subprime lending crisis & 0.044 \\
F-statistic & 0.047 \\
$\mathrm{R}^{2}$ & 0.069 \\
Part B: Lehman Brothers crisis & 0.072 \\
F-statistic & 0.051 \\
$\mathrm{R}^{2}$ & 0.054 \\
Part C: European sovereign debt crisis & \\
F-statistic & \\
$\mathrm{R}^{2}$ & \\
\hline
\end{tabular}

It can be observed from the above table that the ARCH-LM test result of the Subprime lending crisis is not significant, and there is no ARCH effect. The ARCH-LM test results of the Lehman Brothers crisiss were not significant and there was no ARCH effect. The results of the ARCH-LM test for the European sovereign debt crisis were not significant and there was no ARCH effect.
6) ARCH test result

Regression test equation of ARCH model:

$$
C S A D_{t}=\alpha_{0}+\beta_{1}\left|R_{m}\right|+\beta_{2}\left(R_{m}\right)^{2}+\varepsilon_{t}
$$

TABLE VI. ARCH TEST RESULTS

\begin{tabular}{|cccc|}
\hline & Subprime lending crisis & Lehman Brothers crisis & European sovereign debt crisis \\
\hline$\alpha$ & $0.016(1.483)$ & $0.009(0.675)$ & $-0.003(-0.726)$ \\
$\beta_{1}$ & $-2.236(-2.095)^{* *}$ & $-1.222(-1.511)$ & $0.566(0.929)$ \\
$\beta_{2}$ & $24.626(1.825)^{* *}$ & $21.409(0.675)$ & $-27.020(-2.168)^{* *}$ \\
$R^{2}$ & 0.119 & 0.188 & 0.258
\end{tabular}

Note: *,** and *** represent statistical significance at the $10 \%, 5 \%$ and $1 \%$ levels, respectively.

This study uses the regression test equation of the ARCH model to check whether the Shanghai Composite Index has an ARCH effect. The results are as shown in the above table.

In the Subprime leading crisis and the Lehman Brothers crisis, the herding behavior in the stock market is not obvious, mainly due to the company's own reasons, there will be a suspension of trading on certain trading days. If there are major issues such as restructuring, it may be suspended for a longer time. Therefore, after processing, the amount of valid data during the event is finally obtained, and the verification result is that the herding behavior is not obvious in the event.

In the European sovereign debt crisis, there was a herding behavior in the stock market, and herding behavior was significant.

\section{7) GARCH results analysis}

Based on the Shanghai composite index yields of the three financial events, the GARCH model checks the stock market returns during these three events to explore the extent to which crisis affect the herding behavior and stock market volatility. This study uses the GARCH $(1,1)$ test, and the results are shown in Table 7:

The regression test equation of the GARCH model:

$$
\begin{gathered}
R_{m t}=\sigma_{0}+\beta_{1}\left|R_{m}\right|+\beta_{2} C S A D_{t}+\varepsilon_{t} \\
\sigma_{t}^{2}=\alpha_{01}+\alpha_{02} \sum_{x=1}^{p} \varepsilon_{t-1}^{2}+\beta_{01} \sum_{j=1}^{t} \sigma_{t-j}^{2}+\beta_{02} * C S A D_{t}
\end{gathered}
$$


TABLE VII. GARCH RESULTS ANALYSIS

\begin{tabular}{|cccc|}
\hline & $\begin{array}{c}\text { Subprime lending } \\
\text { crisis }\end{array}$ & $\begin{array}{c}\text { Lehman Brothers } \\
\text { crisis }\end{array}$ & $\begin{array}{c}\text { European sovereign debt } \\
\text { crisis }\end{array}$ \\
\hline Mean & Coefficient & Coefficient & Coefficient \\
\hline$\alpha_{0}$ & $0.011(2.712)^{* * *}$ & $0.001(0.469)$ & $-0.000(-0.076)$ \\
$\beta_{1}$ & $2.194(2.802)^{* * *}$ & $1.024(1.430)^{*}$ & $0.344(0.607)$ \\
$\beta_{2}$ & $-24.613(-2.519)^{* * *}$ & $-21.128(-1.427)^{*}$ & $-27.067(-1.11)$ \\
\hline Variance & & & $-0.000(-0.806)$ \\
\hline$\alpha_{01}$ & $-0.000(-0.320)$ & $-0.000(-0.366)$ & $-0.054(-1.116)$ \\
$\alpha_{02}$ & $-0.061(-0.673)$ & $0.052(0.354)$ & $0.360(1.038)$ \\
$\beta_{01}$ & $0.305(0.583)$ & $0.075(0.248)$ & $0.009(1.768)^{* *}$ \\
$\beta_{012}^{*}$ & $0.015(1.921)^{* *}$ & $0.028(1.529)^{*}$ & $0.051(0.822)$ \\
ARCH-LM & $0.043(0.837)$ & $0.069(0.794)$ & \\
\hline
\end{tabular}

Note: *,** and *** represent statistical significance at the $10 \%, 5 \%$ and $1 \%$ levels, respectively.

In the remuneration part, all of the expected risk coefficient $\sigma_{1}$ are significantly positively correlated, indicating that stock returns and volatility are significantly positively correlated, and all of the dummy variable $\sigma_{2}$ are significantly negatively correlated, indicating stock market remuneration have significant negative correlation with the Subprime leading crisis, Lehman Brothers Crisis and European sovereign debt crisis, respectively. In the volatility part, the dummy variable $\beta_{2}$ have significant positive correlation, indicating that the volatility of the stock market have significant correlation with the remuneration of the Subprime lending crisis, Lehman Brothers Crisis and European sovereign debt crisis respectively. All of the ARCH-LM test results are non-dominant, indicating that the data is stable and reliable.

\section{CONCLUSION}

This paper analyzes the financial crisis that occurred during the periods of financial crisis of 2008 to 2010 . We selects the Shanghai composite index rate of return during this period, and then establishes a model to measure the herding behavior in the market and uses the GARCH model to identify the behavior of the herding behavior and the stock market volatility. Finally, we get the conclusions through the combination of theory and model.

We use the regression test equation of the ARCH model to check whether the Shanghai Composite Index has an ARCH effect, and we can get the following conclusions: First, in the single event period, if the test result is not obvious in the stock market, the main reason is the processing of missing data. Second, in the long run, in the case of a large amount of effective data, it is possible to detect the existence of herding behavior in China's stock market. Then, we further use the GARCH model to check the stock market return rate of the three financial crises, and to explore the impact on the behavior of the herding behavior and the stock market volatility during the crisis, we find that stock returns are positively correlated with market volatility, and stock market returns are significantly negative with period events. In addition, in the volatility part, the volatility of the stock market has a significant correlation with the compensation of events.

In response to the herding behavior in Chinese market, we have put forward several policy recommendations for the various participants in the market: for the regulatory layer, they should truly regulate the market without affecting the development of the market itself; for listed companies, it is necessary to standardize information disclosure behavior; for investors, it is necessary to strengthen investment education, fully recognize the risks of the market, rationalize investment, and have the ability to judge independently.

\section{REFERENCES}

[1] Bollerslev, T. (1986). Generalized Autoregressive Conditional Heterskedasticity. Journal of Econometrics, 31(3), 307-327.

[2] Camara, O. (2017). Industry herd behaviour in financing decision making. Journal of Economics \& Business, 94, 32-42.

[3] Chang, E. C., Cheng, J. W., \& Khorana, A. (2000). An examination of herd behavior in equity markets: An international Perspective. Journal of Banking \& Finance, 24(10), 1615-1679.

[4] Chiang, T. C., \& Zheng, D. (2010). An empirical analysis of herd behavior in global stock markets. Journal of Banking \& Finance, 34(8), 1911-1921.

[5] Christie, W., \& Huang, R. (1995). Following the Pied Piper: Do Individual Returns Herd around the Market? Financial Analyst Journal, 51(4), 31-37.

[6] Engle, R.F., Lilien, D.M., \& Robins, R.P. (1987). Estimating Time Varying Risk Premia in the Term Structure: the ARCH-M Model. Econometrica, 55(2), 391-107.

[7] Filip, A., Pochea, M., \& Pece, A. (2015). The herding behavior of investors in the CEE stocks markets. Procedia Economics \& Finance, 32, 307-315.

[8] Guo, L., \& Wu, C. F. (2004). An empirical study on the rational and irrational herd in Chinese stock market. Management Review, 16(11), 53-57.

[9] Hwang, S., \& Salmon, M. (2001). A New Measure of Herding and Empirical Evidence. Working paper.

[10] Hwang, S., \& Salmon, M. (2008). Sentiment and Beta Herding. Journal of Empirical Finance, 3, 565-601.

[11] Shah, M. U. D., Shah, A., \& Khan, S. U. (2017). Herding behavior in the Pakistan stock exchange: Some new insights. Research in International Business \& Finance, 42, 865-873.

[12] Tan, L., Chiang, T. C., Mason, J. R. \& Nelling, E. (2008). Herding behavior in Chinese stock markets: An examination of $\mathrm{A}$ and $\mathrm{B}$ shares. Pacific-Basin Finance Journal, 16(1-2), 61-77.

[13] Yao, J., Ma, C. C., \& He, W. P. (2014). Investor herding behaviour of Chinese stock market. International Review of Economics \& Finance, 29(1), 12-29.

[14] Zheng, D. Z., Li, H. M., \& Chiang, T. C. (2017). Herding within industries: Evidence from Asian stock markets. International Review of Economics \& Finance, 51, 487-509.

[15] Zhou, R. T., \& Lai, R. N. (2009). Herding and information based trading. Journal of Empirical Finance, 16(3), 388-393. 